\title{
Combinaison d'un SMA et d'un SIG pour aider à la prospection pétroarchéologique. Exploration d'une approche multi-agents dans la modélisation des parcours naturels du silex.
}

\section{Combination of an MAS and a GIS to assist in petro-archaeological prospecting. Exploration of a multi-agent approach in modelling natural flint paths.}

\author{
Christophe Tufféry ${ }^{1}$, Paul Fernandes ${ }^{2}$, Vincent Delvigne ${ }^{3}$, André Morala ${ }^{4}$ \\ ${ }^{1}$ Inrap, 121 rue d'Alésia - CS 20007 - 75685 PARIS Cedex 14, christophe.tuffery@inrap.fr \\ ${ }^{2}$ Paléotime, 6173 rue Jean Séraphin Achard Picard 38250 Villard-de-Lans, paul.fernandes@paleotime.fr \\ ${ }^{3}$ Service de Préhistoire, Université de Liège, place du XX août, Liège, Belgique, vincent.delvigne@hotmail.fr \\ ${ }^{4}$ UMR 5199 PACEA, Université de Bordeaux, bâtiment B8, allée Geoffroy Saint Hilaire, 33615 Pessac Cedex, \\ andre.morala@orange.fr
}

(Le texte et les illustrations ont déjà été partiellement publiés dans Fernandes et al. 2018. Ces travaux ont également fait l'objet de la communication Tufféry C. et al. 2017)

RÉSUMÉ. L'utilisation présentée ici de la simulation multi-agents (SMA), qui ont été engagés de façon exploratoire, vise à simuler les parcours théoriques potentiels des fragments de roches siliceuses, selon un modèle gravitaire et des données d'altimétrie de diverses bases de données d'altitude de l'IGN. L'objectif est de permettre d'identifier des zones où les fragments de roches siliceuses érodées ont pu être concentrés. II s'agit ainsi de cibler les actions de prospection sur ces zones théoriques pour avoir le plus de chances de retrouver des concentrations de ces fragments rocheux.

Cette démarche s'inscrit dans le cadre des travaux de plusieurs Projets Collectifs de Recherche (PCR) "Réseaux de lithothèques" qui sont en cours. L'un des axes de travail de ces projets est d'améliorer la connaissance spatiale des formations à silex dont les populations préhistoriques ont pu extraire des ressources pour leurs besoins. Les grands principes de la SMA seront évoqués et des premiers résultats, obtenus à l'aide du logiciel NetLogo et d'un modèle gravitaire, sont présentés et discutés.

ABSTRACT. The use of multi-agent simulation (MAS), which were engaged as an exploration, aims to simulate potential theoretical paths of siliceous rock fragments, according to a gravity model and altimetry data from various IGN altitude databases. The objective is to identify areas where eroded siliceous rock fragments may have be concentrated. The aim is therefore to target prospecting activities on these theoretical zones to have the best chance of finding concentrations of these rock fragments. This approach is part of the work of several on going Projets Collectifs de Recherche (PCR) "Réseaux de lithothèques". One of the working axes of these projects is to improve the spatial knowledge of flint formations whose prehistoric populations were able to extract resources for their needs. Main principles of SMA and first results, obtained using NetLogo software and a gravity model, are presented and discussed.

MOTS-CLÉS. prospection, pétroarchéologie, SMA, SIG, modélisation.

KEYWORDS. prospecting, petroarchaeology, MAS, GIS, modelizing.

\section{Introduction}

L'identification des sources d'approvisionnement en matières premières est aujourd'hui une thématique commune à tous les préhistoriens. En effet, l'étude de la provenance du matériel lithique, parmi lequel le silex occupe une place majeure, permet de replacer les sites dans un maillage territorial et de nous renseigner sur la mobilité des groupes humains. Elle constitue, de ce fait, une archive de premier ordre pour aborder les sociétés préhistoriques et leur évolution. 
Dans ce contexte, la caractérisation précise des ressources lithiques revêt un intérêt particulier car elle permet :

- de retracer les espaces parcourus et d'identifier des modes de transport des artefacts qui renseignent sur les formes sociales, les régimes de mobilité, l'occupation des territoires et éventuellement l'identification des terroirs ;

- de matérialiser et de caractériser les interactions entre des entités culturelles distinctes et de questionner les modes d'accès aux sources, directs ou contrôlés par exemple.

Depuis plus d'une dizaine d'années, plusieurs projets collectifs de recherche (PCR) tentent de mettre au point et d'utiliser des cadres conceptuels, terminologiques et méthodologiques communs afin d'améliorer la description des gîtes de matières premières lithiques, pour alimenter des lithothèques cohérentes entre elles.

L'un des axes de travail de ces PCR, en cours de regroupement dans un Groupement De Recherche (GDR), vise à la caractérisation des matières premières identifiées sur le terrain en prenant en compte la notion de chaîne évolutive (Fernandes et Raynal, 2006). Ce nouvel outil de diagnose élargit à la préhistoire les raisonnements sur le rapport entre silex et environnements. Il permet d'associer de façon raisonnée les différentes approches. En effet, que les diagnostics soient pétrologiques ou physicochimiques, elles nécessitent une prise en compte à haut niveau des processus d'altération générés par la redistribution des matériaux dans l'environnement et susceptibles de modifier radicalement certains aspects des géomatières comme des objets archéologiques. Ce renouvellement conceptuel et méthodologique, basé sur des approches interdisciplinaires et multiscalaires, permet de sortir de nombreuses impasses en termes de caractérisation de la provenance des matériaux siliceux (Fernandes 2012).

Dès lors, il apparaît indispensable d'améliorer la connaissance des géomatériaux actuels et de pouvoir retracer au mieux les parcours naturels suivis par ces ressources, depuis leur gite d'origine jusqu'à leurs gîtes de fin de déplacement naturel. Les opérations de prospection nécessitent donc de pouvoir reconstituer au mieux ce qu'ont pu être ces parcours naturels, essentiellement sous l'influence de la gravité, depuis les formations les plus sommitales jusqu'aux formations les plus basses dans les pentes et les thalwegs, où des nodules de ces ressources peuvent être retrouvés actuellement. Cette approche permet de mieux structurer les opérations de prospection et de caractérisation en proposant une méthode fondée sur les interactions entre silex et environnements.

C'est dans ce cadre que nous avons pu participer du 18 au vendredi 23 Juin 2017 à Oléron à l'école thématique MAPS10 1 , qui nous a permis de nous initier à la modélisation multi-agents et de commencer à explorer les possibilités d'utilisation de cette approche pour la modélisation des parcours naturels du silex ${ }^{2}$.

$\mathrm{Au}$ retour de cette formation, nous avons travaillé avec un jeu de données réelles provenant du fichier des polygones des formations à silex sur la Dordogne produit dans le cadre du PCR Nouvelle-

\footnotetext{
${ }^{1}$ http://maps.hypotheses.org/evenement-a-venir/maps-10

${ }^{2}$ MAPS10 est une école thématique organisée dans le cadre du réseau MAPS (Réseau thématique de modélisation multi-agents appliquée aux phénomènes spatialisés). Le programme de la formation que nous avons suivi est fourni en annexe 4 . Cette manifestation est soutenue par le CNRS, le Réseau National des Systèmes Complexes, le Labex DYNAMITE, I'UMR 7324 CITERES (dont nous faisons partie comme chercheur associé au Laboratoire Archéologie et Territoires).
}

La formation sur 5 jours consiste en une initiation aux principes de la modélisation multi-agents sous la forme d'une série de conférences et de la réalisation d'un projet collectif (par une équipe de 5 à 7 stagiaires) autour de l'utilisation du logiciel modélisation multi-agents. Lors de ce stage, nous avons commencé à explorer certaines des possibilités d'utilisation du logiciel libre de NetLogo, à partir de données théoriques. NetLogo est un logiciel libre de simulation multi-agents, développé depuis la fin des années 90 par une communauté de contributeurs, parmi lesquels U. Wilensky (Wilensky U, 1999, 2006). 
Aquitaine (Morala et al. 2016). Pour le terrain, nous avons utilisé un extrait de la BD Alti de l'IGN à $75 \mathrm{~m}^{3}$ puis nous avons utilisé un extrait du RGE à $25 \mathrm{~m}^{\text {de }}$ l'IGN $^{4}$ sur une zone plus limitée comprise à l'intérieur de la zone précédente (figure 1).
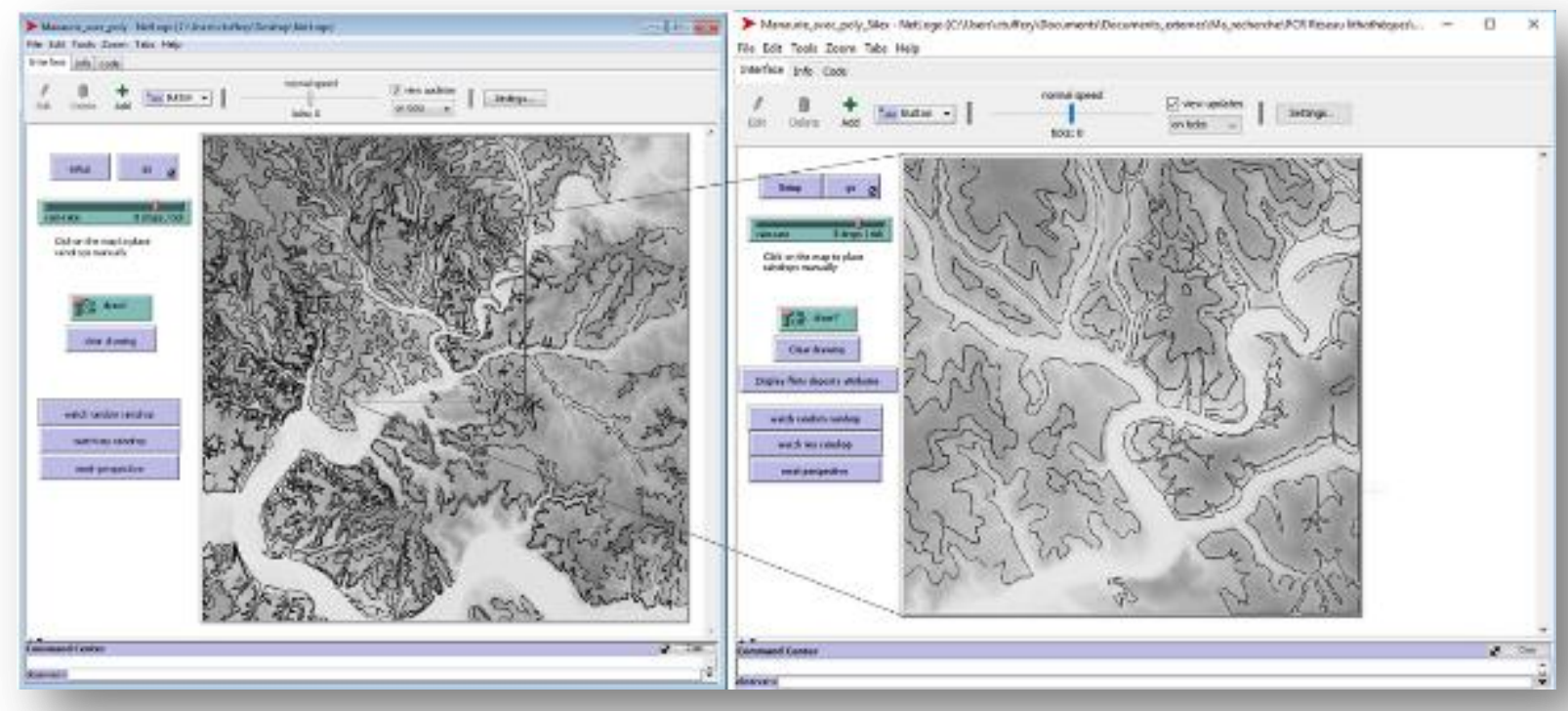

Figure 1. Affichage dans NetLogo des contours des formations à silex (en noir) sur un fond orographique (BD Alti de l'IGN à $75 m$ à gauche; BD Alti de l'IGN à $25 m$ à droite).

\section{Principes de fonctionnement de NetLogo et présentation des premiers travaux réalisés}

L'interface de NetLogo est entièrement paramétrable selon les fonctionnalités souhaitées et les lignes de codes associées.

Pour la modélisation des parcours naturels théoriques des silex, nous avons utilisé l'un des modèles disponibles dans la bibliothèque de modèles du logiciel NetLogo, le modèle Grand Canyon (catégorie Earth Science $)^{5}$. Il s'agit d'un modèle de type gravitaire, qui s'appuie sur le principe du déplacement d'une goutte d'eau, constituant ici l'agent du modèle, d'un point haut à un point bas selon la plus grande pente. Ce modèle nous est apparu, par analogie, le plus proche de notre problématique scientifique.

Selon les principes des études pétroarchéologiques récentes (Fernandes P., 2012), il est admis que les fragments de roches provenant des formations à silex, se sont déplacés des points hauts aux points bas des reliefs selon un modèle gravitaire comme le montre la figure 2 .

\footnotetext{
${ }^{3}$ La BD Alti à 75m fait partie des données de I'IGN qui sont gratuites pour tous les usages selon les termes de la "licence ouverte" : http://professionnels.ign.fr/gratuite-des-donnees

${ }^{4}$ La BD ALTI à 25m fait partie des données de l'IGN auxquelles les organismes d'enseignement et de recherche comme l'INRAP ont accès gratuitement au titre de la licence Education-Recherche.
}

5 Wilensky, U. (2006). NetLogo Grand Canyon model. http://ccl.northwestern.edu/netlogo/models/GrandCanyon. Center for Connected Learning and Computer-Based Modeling, Northwestern University, Evanston, IL. 


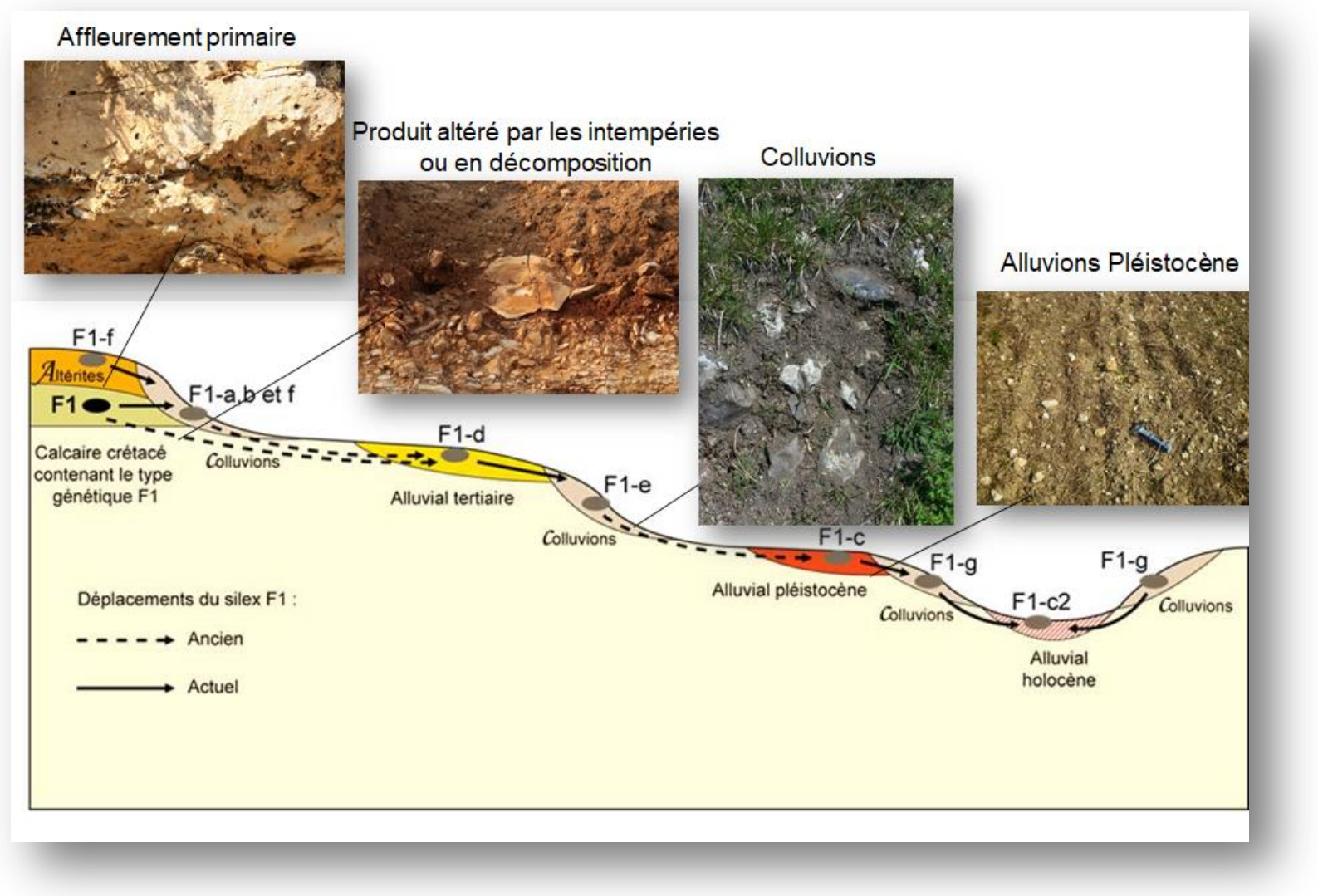

Figure 2. Schéma des déplacements des fragments de roches siliceuses depuis leurs gîtes primaires.

Ainsi, un silex provenant d'un gite primaire (formation en place) est en connexion avec l'ensemble des formations qui se trouvent en aval de cette formation (formations secondaires voire tertiaires) et qu'il alimente, chacune contenant un silex dont le faciès d'altération est différent.

Dans NetLogo, le calcul des pentes entre les pixels du MNT permet de tracer les plus courts chemins et donc de rechercher les points les plus bas vers lesquels les agents sont susceptibles de se rendre. Les agents qui apparaissent sont générées de façon aléatoire par l'application mais la vitesse de déplacement des agents ou encore l'intensité (c'est-à-dire le nombre d'agents apparaissent par unité de temps) peut être paramétrée par l'utilisateur.

Ce modèle est théorique et il ne prend en compte que les valeurs de pente issues du calcul à partir du MNT qui est lui-même un modèle maillé approximatif. A cette étape, et pour l'instant, nous avons décidé de ne prendre en compte autre facteur externe dans le calcul des déplacements des agents. Bien évidemment il est possible d'ajouter d'autres facteurs externes comme par exemple une couverture végétale qui pourrait modifier, au moins localement, les conditions de déplacement des agents. 


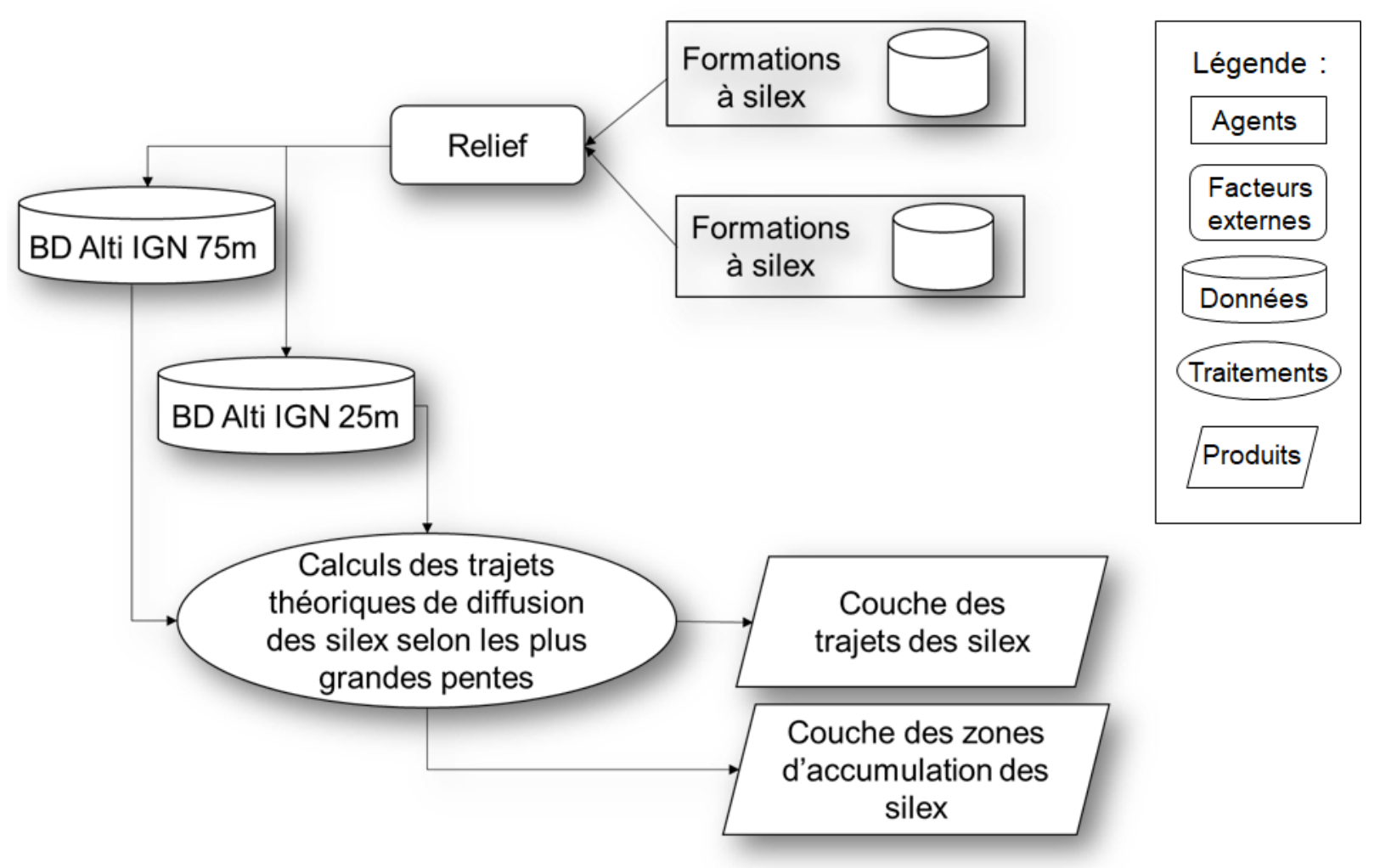

Figure 3. Modélisation de la démarche de calcul des parcours des agents.

Dans NetLogo, le calcul du plus court chemin entre les pixels du MNT, prend en compte les 8 pixels autour de celui qui reçoit la goutte d'eau. Les valeurs d'altitude de chacun de ces huit pixels sont comparées à celle du pixel d'origine de l'agent. Celui-ci sera transféré vers le pixel dont la valeur est la plus basse parmi les huit pixels considérés et ainsi de suite selon un calcul de type itératif (figure 4).

Exemple :

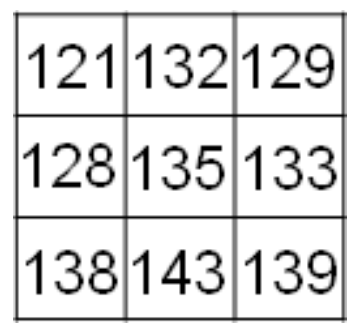

Valeurs des 8 pixels

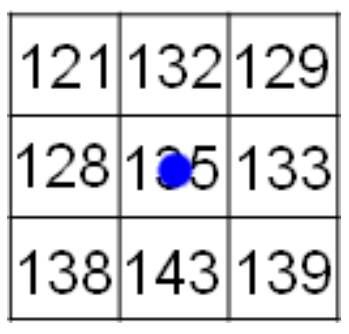

L'agent arrive dans le pixel du centre

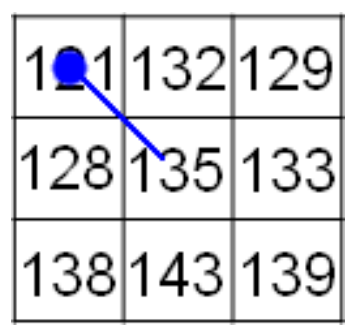

L'agent se déplace vers le pixel dont l'altitude est la plus basse

Figure 4. Principes du calcul dans NetLogo du déplacement des agents selon les valeurs des 8 pixels du MNT se trouvant autour du pixel recevant l'agent.

Dans le cas des données réelles de la BD Alti à $75 \mathrm{~m}$ que nous avons utilisées, le résultat du déplacement des agents montre que leur transfert s'est bien effectué des pixels de plus haute altitude vers ceux de plus basse altitude (figure 5). 
Figure 5. Résultat du parcours d'un agent vers les pixels de plus basse altitude à partir du MNT de la BD Alti à $75 \mathrm{~m}$.

SI on laisse le processus se dérouler, les agents provenant d'un même bassin-versant convergent vers le thalweg le plus proche de ce bassin-versant puis vers le thalweg du bassin-versant situé en aval du précédent et ainsi de suite (figure 6).

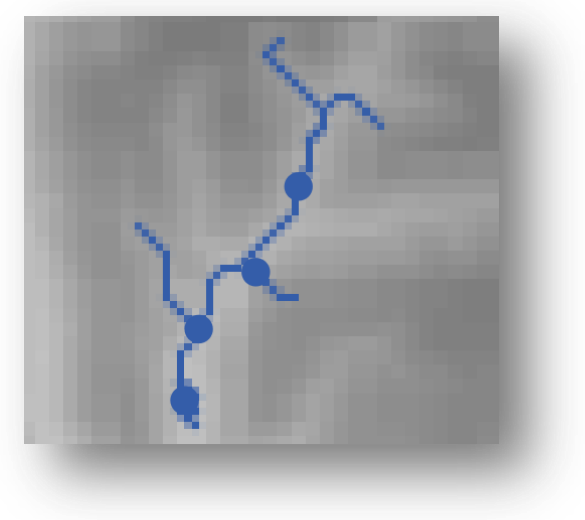

Figure 6. Résultats des parcours de plusieurs agents ver les thalwegs d'un bassin-versant.

La figure 7 montre le résultat d'un calcul en cours des transferts des agents. 


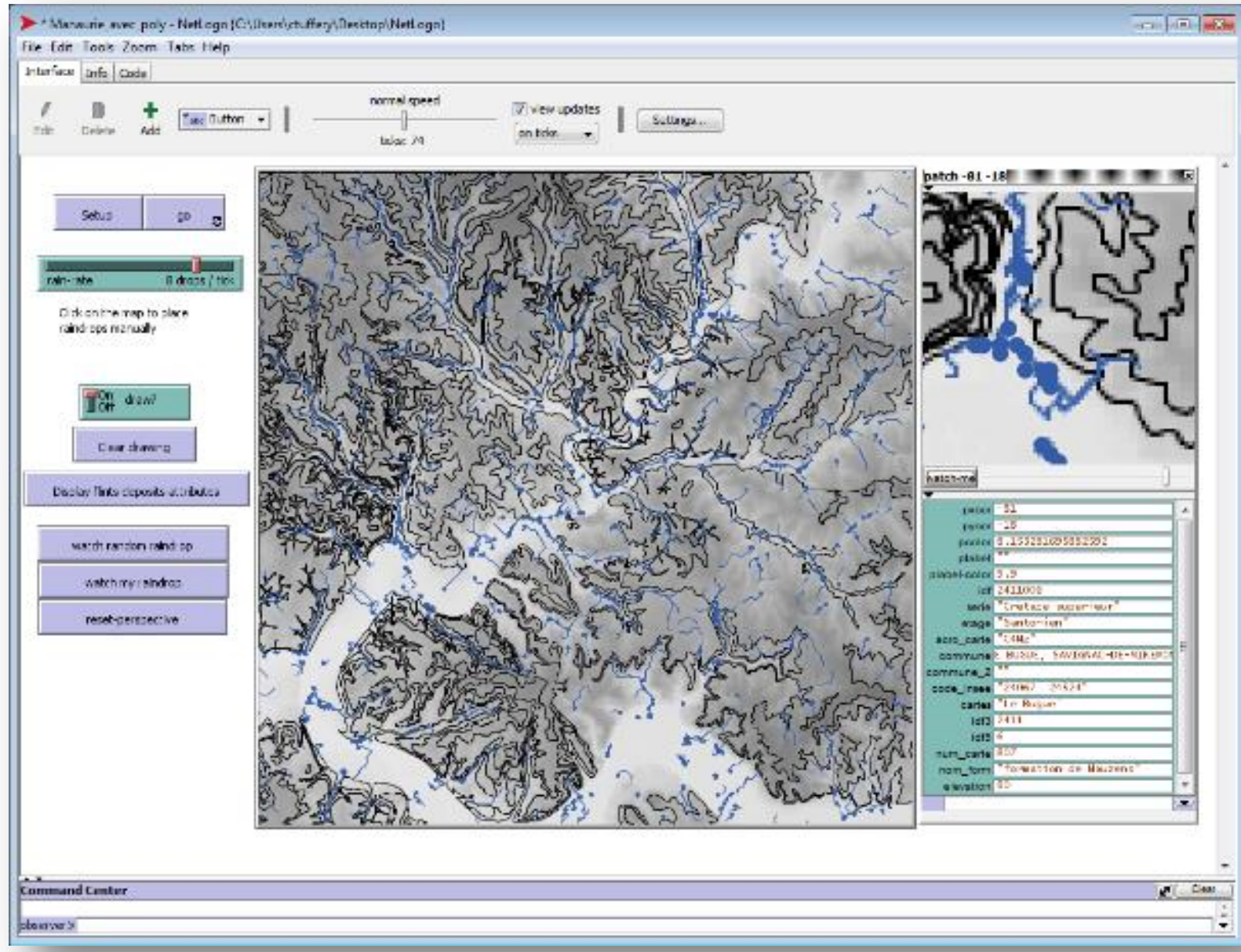

Figure 7. Affichage dans NetLogo du déplacement de agents selon les plus grandes pentes de la topographie avec l'option d'affichage du tracé suivi par les agents sur le terrain.

On peut ajouter ses propres agents et suivre leur déplacement. Ici ils sont représentés en couleur rouge pour les distinguer des autres agents en bleu générés aléatoirement par l'application (figure 8). 


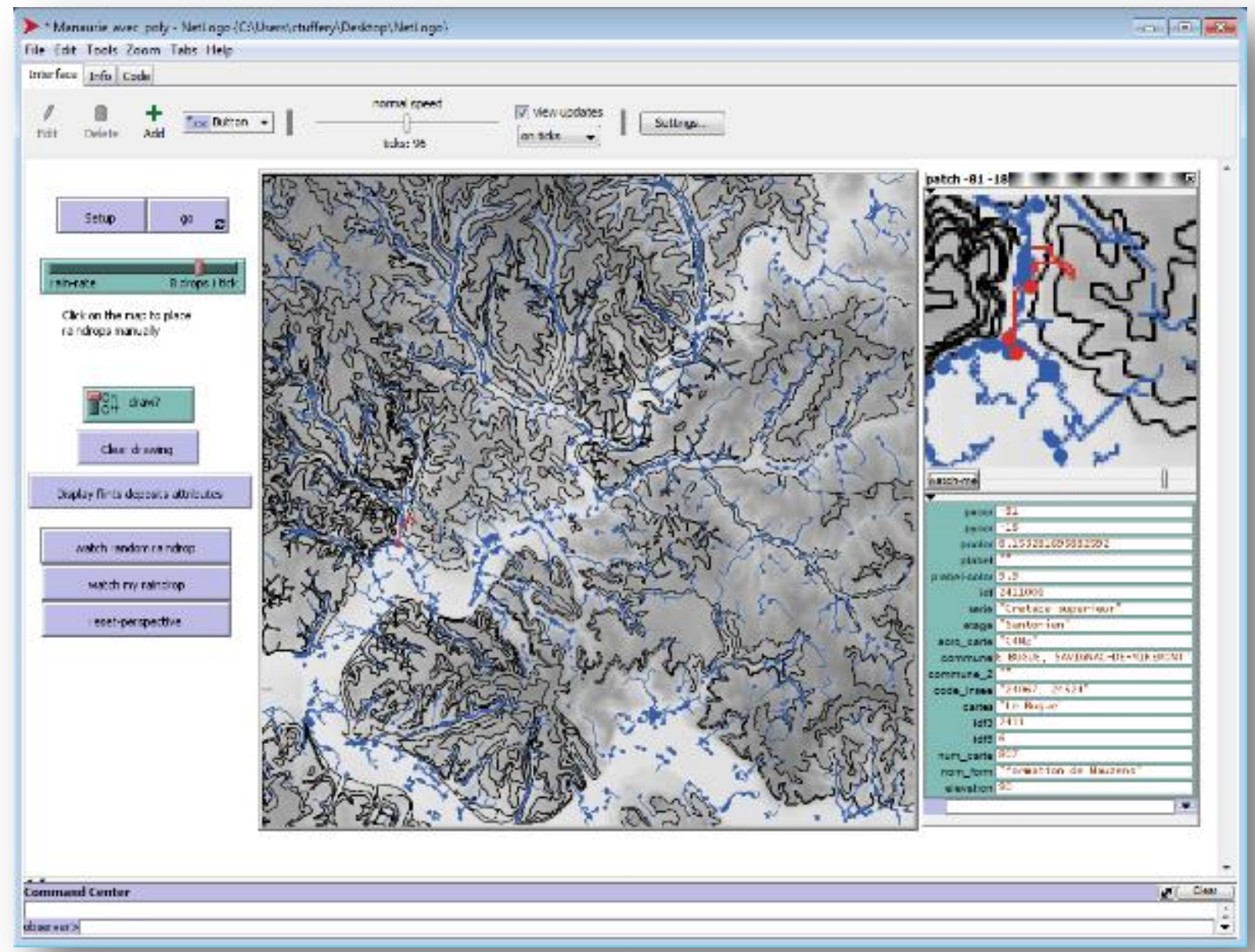

Figure 8. Affichage d'un agent et de son déplacement en rouge dans la fenêtre cartographique principale et dans la fenêtre de zoom.

Dans la fenêtre de zoom, on peut voir le déplacement de l'agent avec un plus grand niveau de détail, qu'on peut changer interactivement avec la réglette de zoom associée à cette fenêtre.

Quand un agent semble stagner dans une zone, c'est qu'il ne trouve pas de points de plus basse altitude vers lesquels se diriger. Il se déplace alors de façon aléatoire entre les points les plus bas de même altitude que celui dans lequel il est parvenu. C'est le cas de zones de cuvette sans évacuation possible. Sinon l'agent demeure sur le même pixel et ne bouge plus.

Il faut noter qu'on peut modifier le type de symbole utilisé ainsi que sa taille. Il existe une bibliothèque riche de symboles différents et on peut ajouter ses propres symboles.

Si on laisse le calcul du déplacement des agents arriver à terme, on obtient une carte des zones de concentration des agents dans les points les plus bas du MNT (figure 9). 


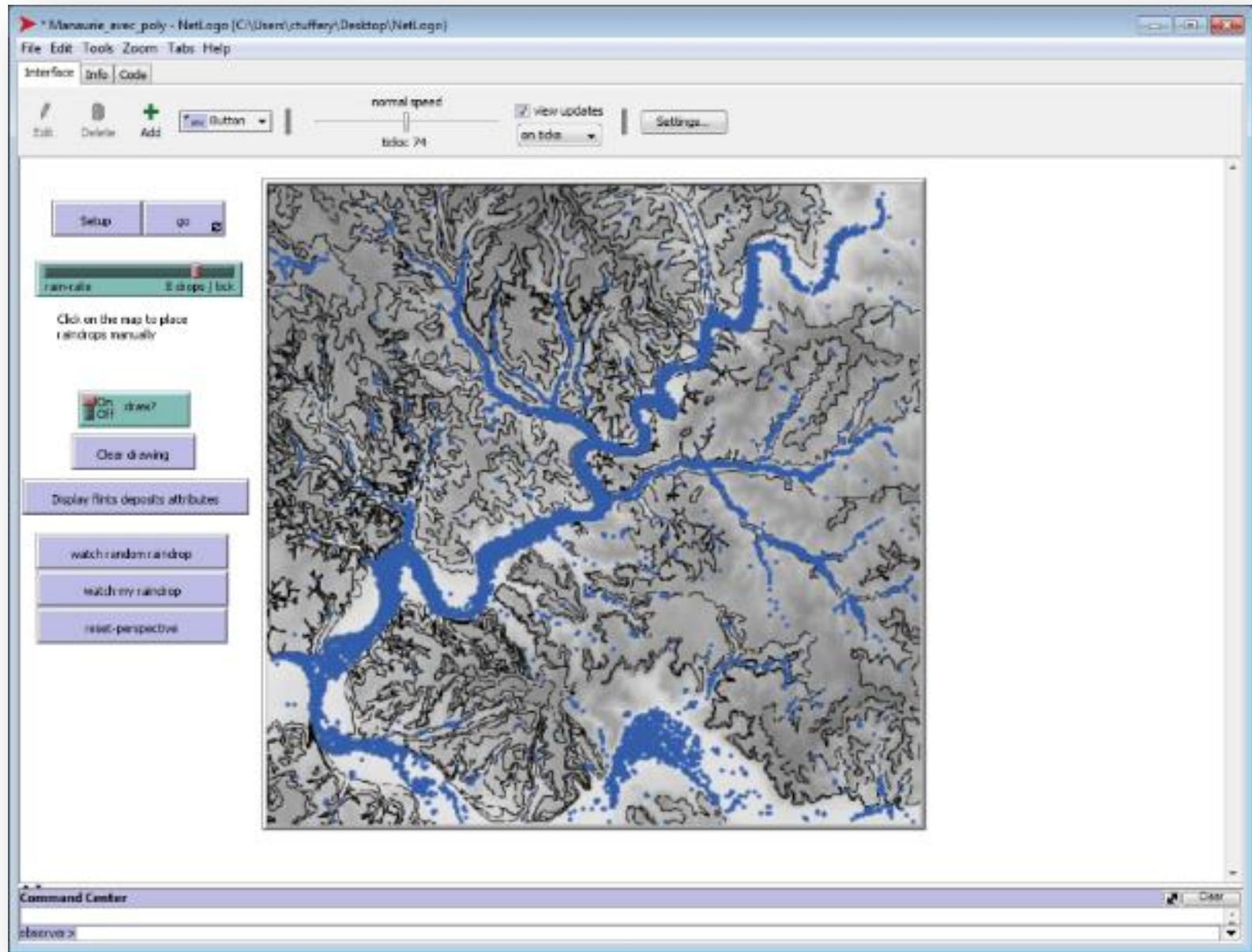

Figure 9. Affichage des zones de concentration des agents avec la BD Alti à $75 \mathrm{~m}$ et des contours des formations à silex.

Ces zones de concentration dessinent le tracé du réseau hydrographique des fonds de vallée.

Après ce premier travail à partir d'un extrait de la $\mathrm{BD}$ Alti à $75 \mathrm{~m}$ de l'IGN, nous avons procédé exactement de la même façon sur une zone plus réduite avec la BD Alti à $25 \mathrm{~m}$ de $1^{\prime} \mathrm{IGN}^{6}$ (figure 10).

\footnotetext{
${ }^{6}$ Nous avons utilisé la licence Enseignement-Recherche dont bénéficie l'Inrap pour ce type de données entre autres.
} 


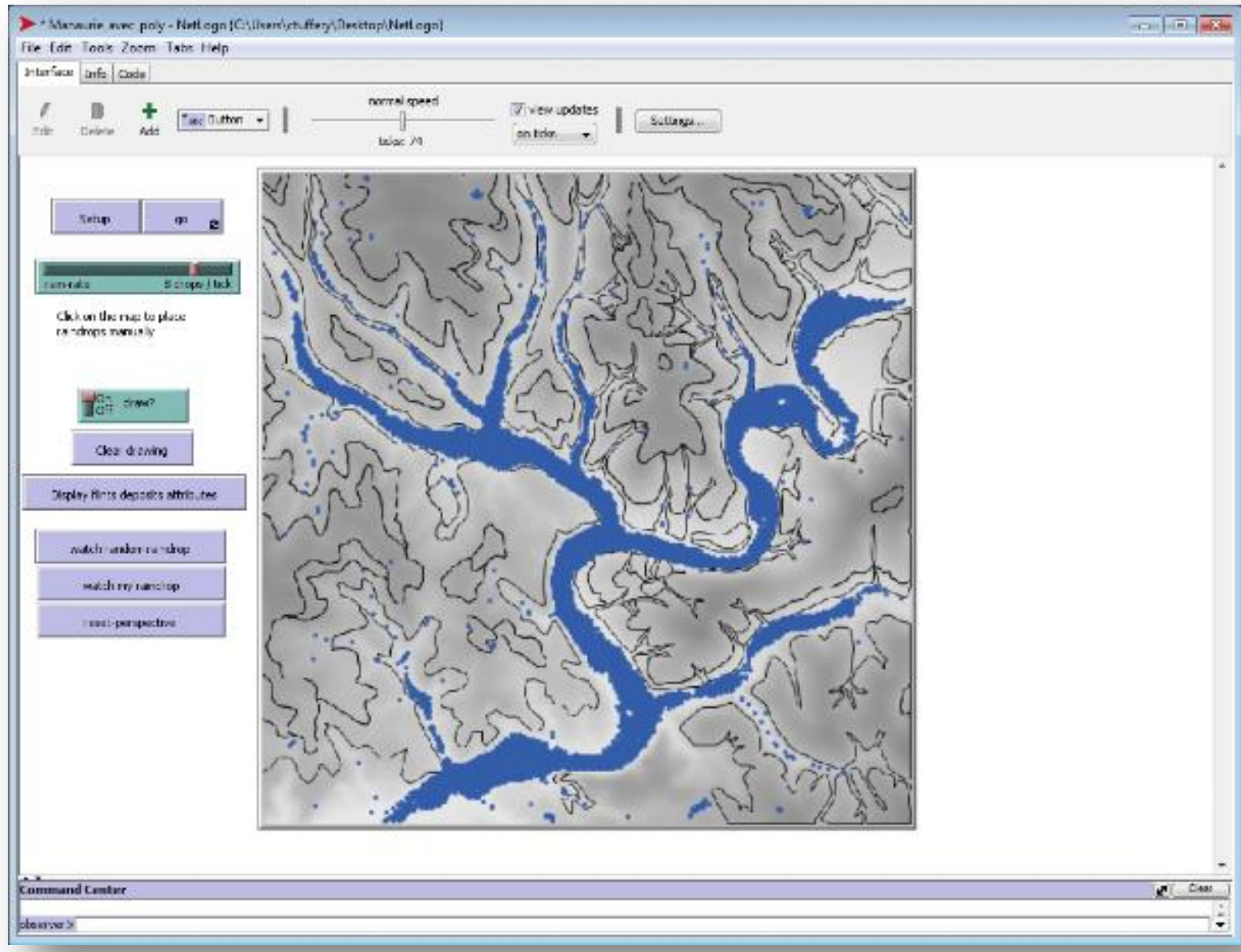

Figure 10. Affichage des zones de concentration des agents avec la BD Alti à $25 \mathrm{~m}$ et des contours des formations à silex.

On peut ainsi comparer les résultats obtenus entre l'utilisation du même modèle pour les deux résolutions différentes du MNT, afin d'évaluer l'effet de la différence de résolution entre ces deux types de données sur les trajets de parcours des agents. La figure 9 obtenue avec la BD Alti à $25 \mathrm{~m}$, peut être ainsi comparée à celle obtenue avec la BD Alti à 75 m (figure 11).
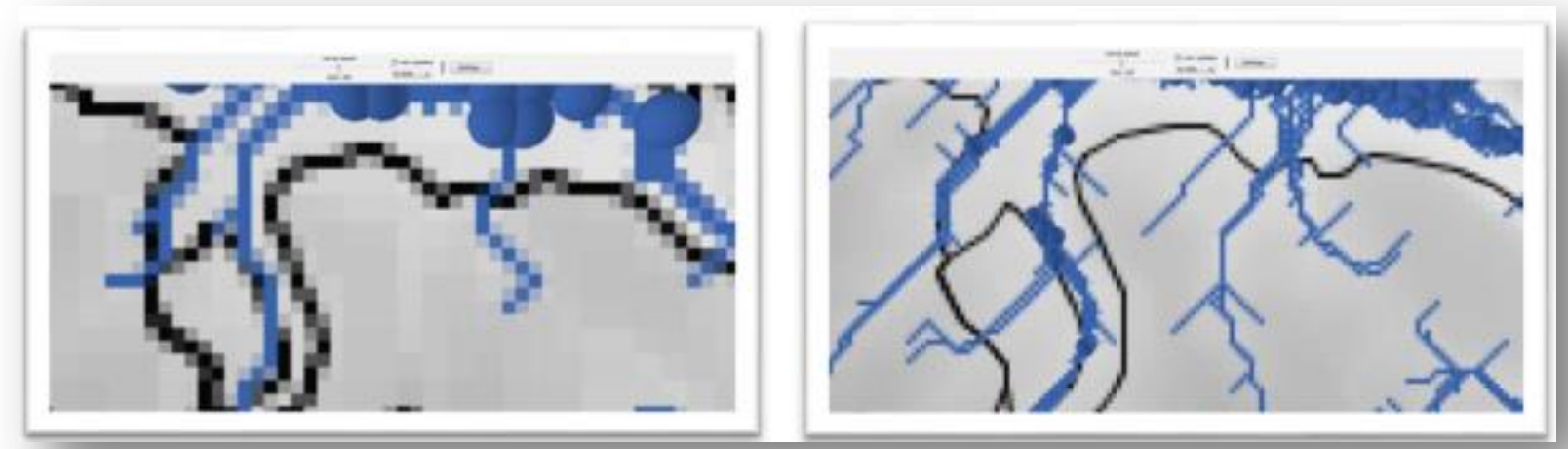

Figure 11. Comparaison sur un même secteur des résolutions différentes des MNT (BD Alti $75 \mathrm{~m}$ et BD Alti $25 \mathrm{~m}$ ) et de leurs effets respectifs sur les parcours des agents. 
Une fois le calcul terminé dans NetLogo, on peut supprimer l'affichage des contours des polygones des formations à silex (en noir) et n'afficher que les zones de concentration des agents (figure 12).

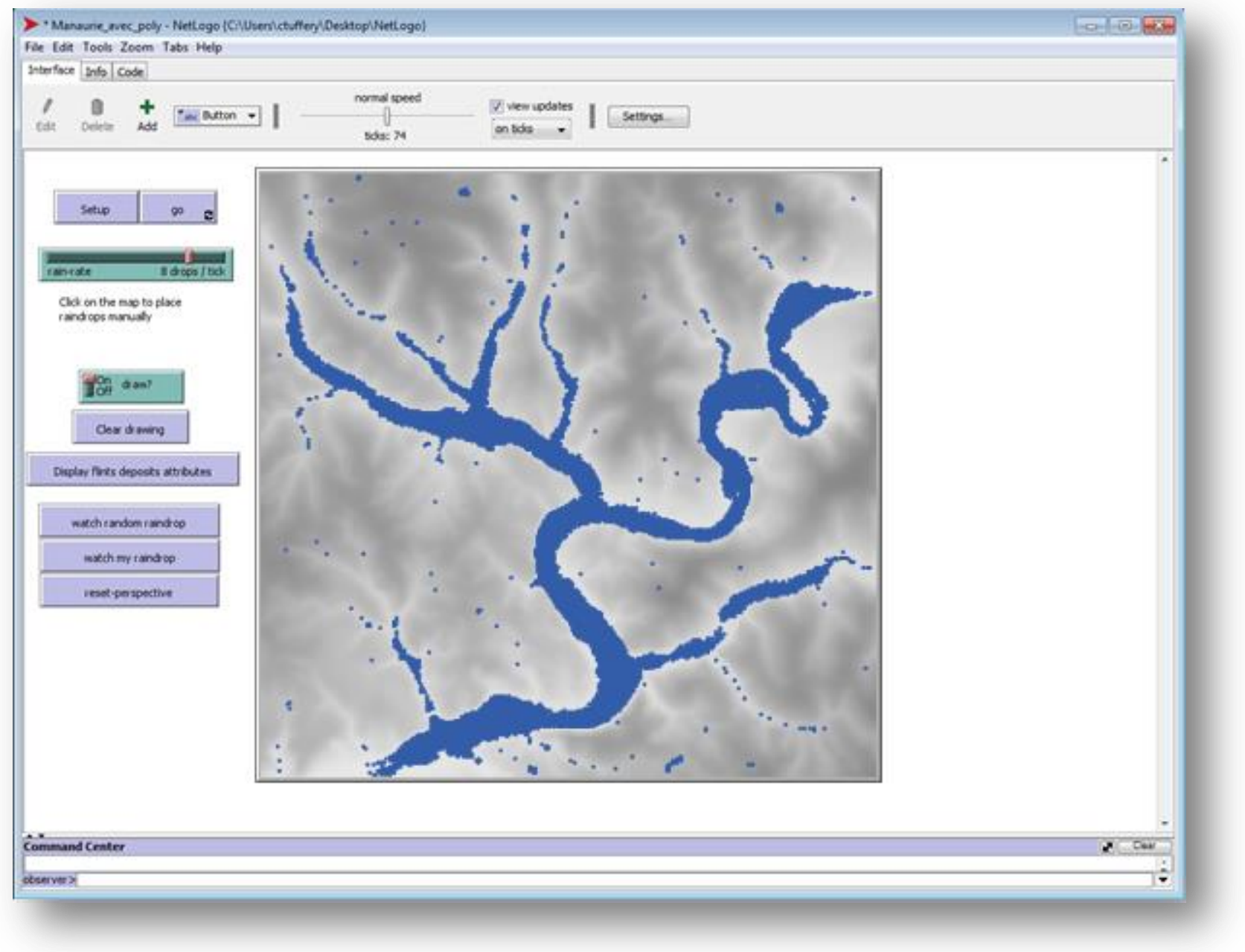

Figure 12. Affichage des zones de concentration des agents avec la BD Alti à $25 \mathrm{~m}$

NetLogo propose aussi un module de visualisation en 3D, sur lequel on peut choisir le niveau de zoom souhaité grâce au menu prévu pour cette fonctionnalité.

On peut choisir là aussi d'afficher les agents (en bleu) générés aléatoirement par l'application et leurs trajets sur le terrain, à côté desques on peut afficher aussi ses propres agents (en rouge). Les paramètres de couleur et de forme sont modifiables dans le code (figure 13). 


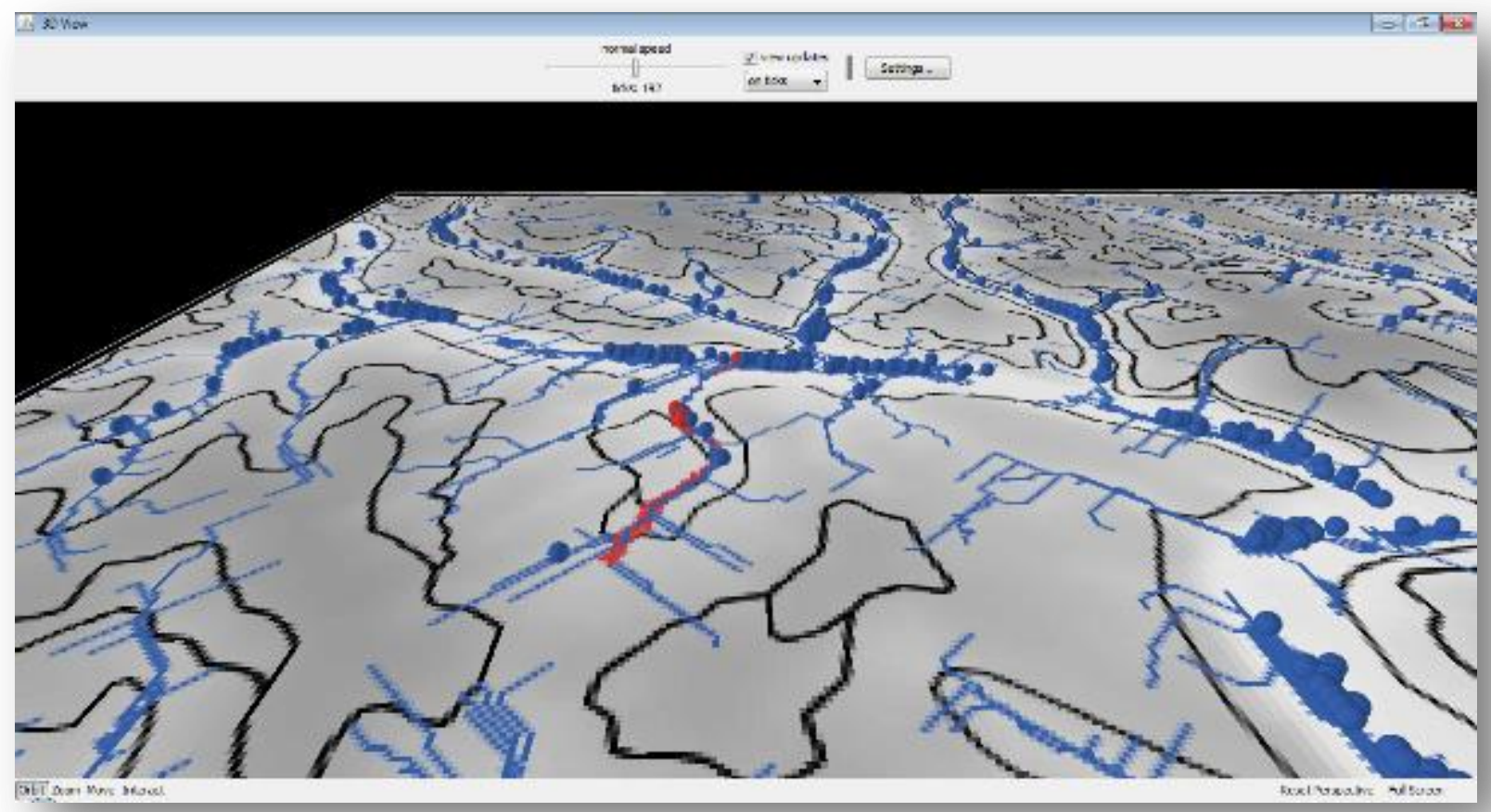

Figure 13. Affichage dans le module 3D de NetLogo d'une vue en perspective du MNT de la BD Alti à $25 \mathrm{~m}$, des contours des formations à silex, des agents générés par l'application (en bleu) et de ses propres agents (en rouge).

L'étape suivante consiste à désactiver à l'affichage les agents (ici en bleu) et à ne retenir que ses propres agents (ici en rouge) pour simuler le déplacement d'un fragment de roche siliceuse depuis sa formation d'origine vers les zones de concentration théorique potentielle du fait de la gravité (figure 14). 


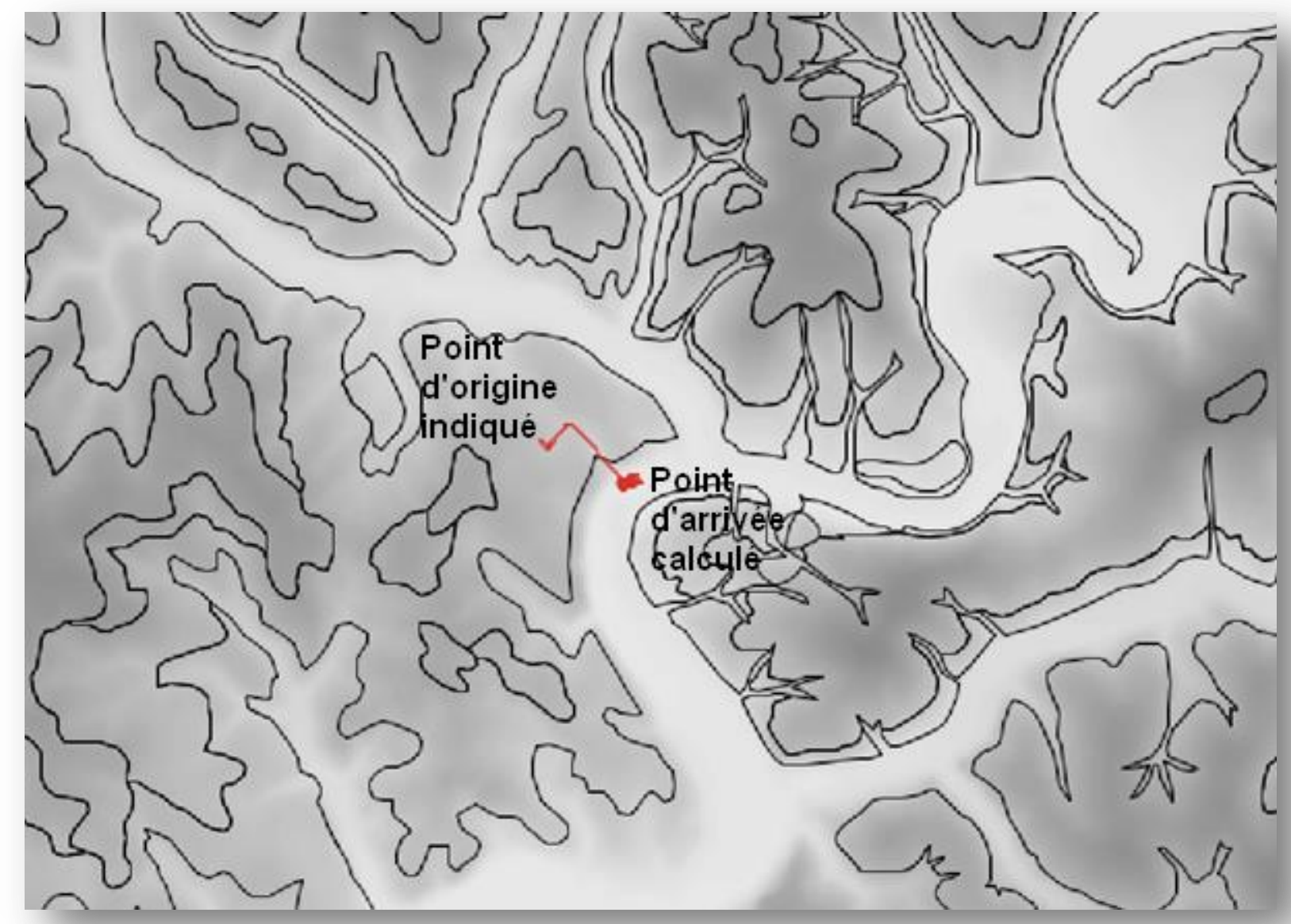

Figure 14. Affichage du déplacement simulé d'un fragment de roche siliceuse de NetLogo avec la BD Alti $25 \mathrm{~m}$.

On peut ainsi multiplier les simulations des itinéraires des roches siliceuses provenant des formations à silex et les comparer les unes par rapports aux autres.

En inversant dans le code le sens de déplacement des roches siliceuses, on peut obtenir l'itinéraire de provenance le plus probable à partir d'un point désigné à l'écran (figure 15). 


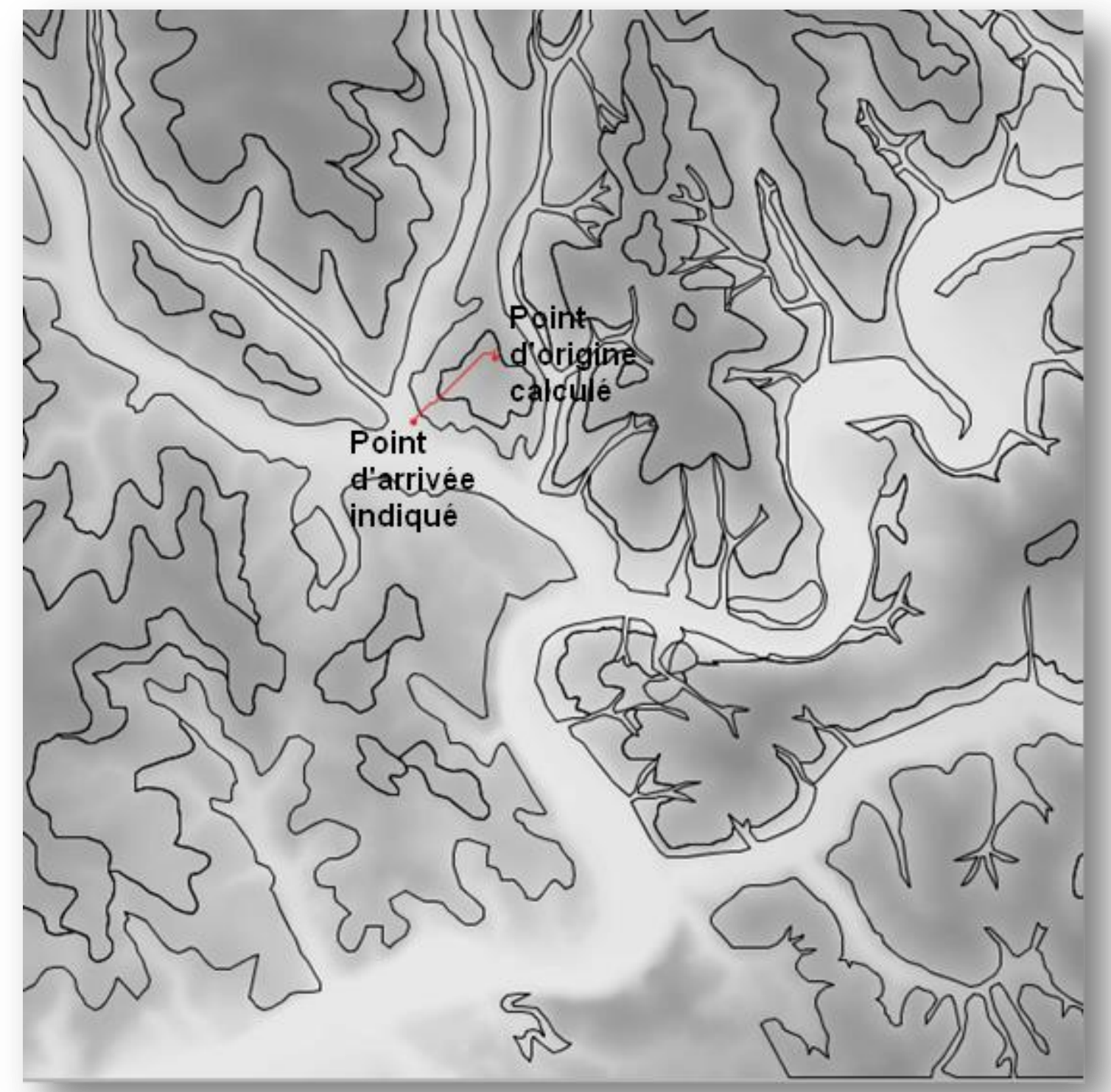

Figure 15. Affichage du déplacement inversé d'un fragment de roche siliceuse de NetLogo simulant l'origine potentielle d'un fragment calculé à partir de l'indication d'un point d'origine en fond de vallée.

Un autre des modèles proposés avec le logiciel NetLogo méritera d'être exploré : le modèle Erosion $^{7}$. Ce modèle consiste en une simulation de l'érosion des sols par l'eau. La pluie tombe sur le terrain et commence à couler vers les zones les plus basses comme dans le modèle Grand Canyon que nous avons utilisé. Sous l'effet des écoulements d'eau, le terrain est érodé. Les modèles d'écoulement de l'eau changent au fur et à mesure du remodelage du terrain. Finalement, un système hydrographique émerge. Il conviendra de voir la complémentarité entre ce modèle et le modèle Grand Canyon.

\section{Exportation des résultats de NetLogo en format image et affichage dans un SIG}

L'étape suivante consiste à exporter dans un logiciel de SIG comme QGis le résultat de ces simulations.

Plusieurs formats d'export sont disponibles dans NetLogo (menu File $>$ Export). Après avoir exploré ces diverses possibilités, nous avons opté pour l'export de la vue (File >Export >Export view). 
Un fichier au format image .png est créé. Pour pouvoir l'afficher ensuite dans un logiciel de SIG comme QGis, il faut créer un fichier texte au format .pgw qui permet le géoréférencement de l'image. Ce fichier doit être modifié pour tenir compte de la résolution de l'image .png et de l'emplacement géographique où cette image doit s'afficher dans le SIG.

Une fois que le fichier .pgw a été enregistré avec les valeurs correctes, le fichier .png peut être affiché dans un SIG comme QGis (figure 16).

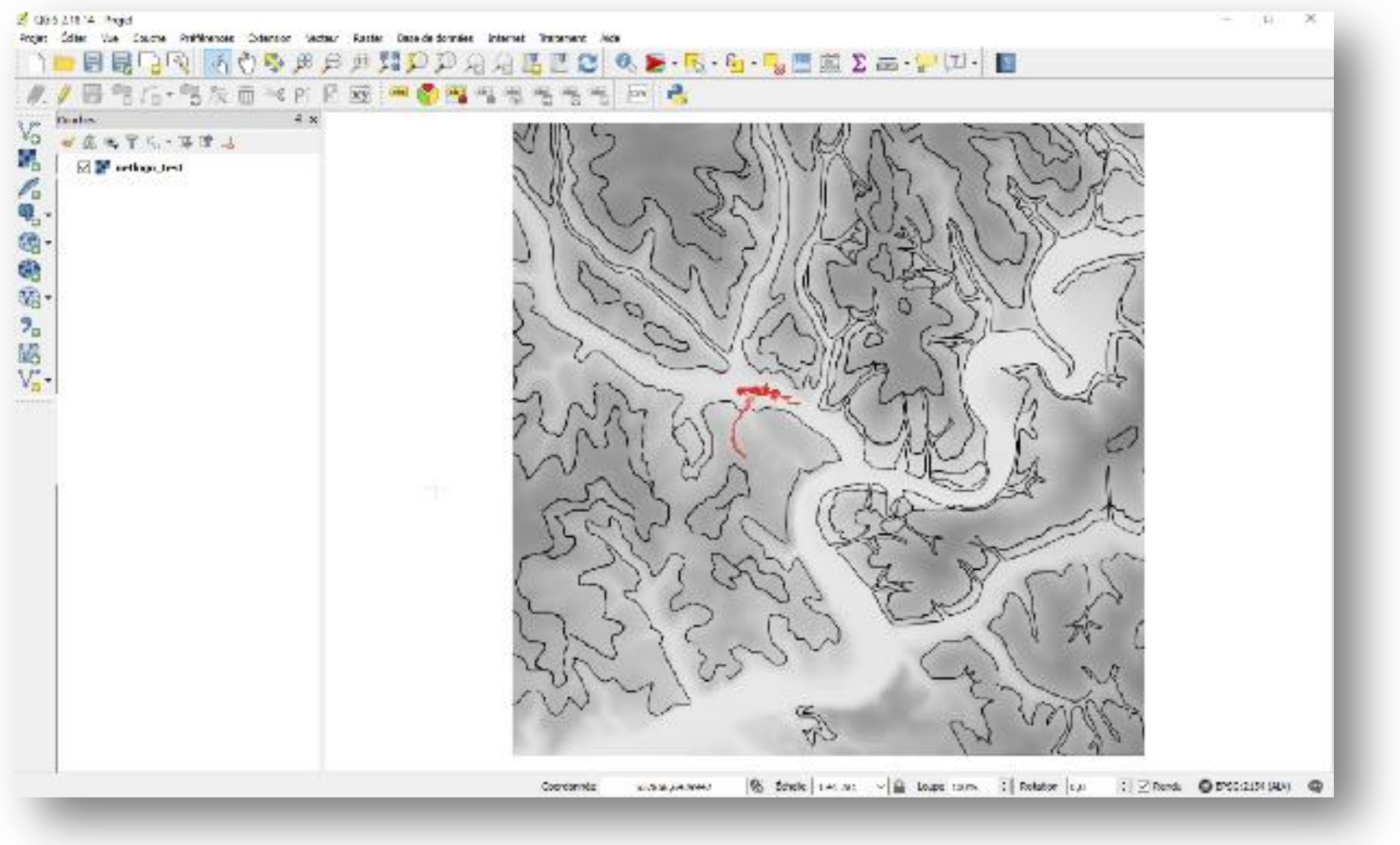

Figure 16. Affichage dans QGis d'un fichier image exporté depuis NetLogo auquel un fichier de géoréférencement a été associé (le fond altimétrique est le même que celui utilisé dans NetLogo pour la simulation).

On peut ainsi exporter de NetLogo toutes les images correspondant à diverses simulations et divers niveaux de zoom et les afficher dans le logiciel de SIG choisi. Il faut créer autant de fichiers .pgw qu'il y a de fichiers exportés au format .png.

L'étape suivante consiste à retenir la ou les simulations qui paraissent d'intérêt en fonction de la résolution des données altimétriques adaptées aux besoins et au niveau d'échelle d'affiche le plus pertinent. Ces simulations permettent d'indiquer des zones de concentration théorique potentielle des fragments rocheux provenant d'une des formations à silex tout en reconstituant leur parcours naturel théorique probable en fonction du seul critère de pente.

Les résultats affichés dans QGis peuvent ensuite être comparés visuellement.

Le lancement de NetLogo peut aussi se faire directement depuis QGis à l'aide d'un bouton d'action à ajouter dans la barre des outils.

Si on refait une simulation dans NetLogo et qu'on en exporte le résultat sous forme de fichier image avec son fichier de géoréférencement, il faut supprimer dans la liste des couches de QGis le fichier image précédent et le remplacer par le nouveau. 
Les résultats des simulations successives qu'il est possible de produire à partir de NetLogo puis d'afficher dans un logiciel de SIG, permettent ainsi d'identifier les zones de concentration des agents de NetLogo. Ces résultats peuvent être comparés avec le résultat des zones du calcul de remplissage dans un logiciel de SIG comme ArcGIS ${ }^{8}$. La comparaison montre une grande cohérence entre ces deux types de calculs.

Par rapport aux résultats de calcul de remplissage disponibles dans un logiciel de SIG comme ArcGIS, l'utilisation combiné du modèle que nous avons adapté dans NetLogo, permet d'enrichir les possibilités de simulation et d'analyse pour répondre spécifiquement à nos besoins. Dans NetLogo, l'utilisateur peut faire plusieurs simulations, changer aisément de points d'origine et/ou de points de destination des trajets potentielles des roches siliceuses selon le modèle gravitaire utilisé. Les résultats peuvent être aisément exportés dans un logiciel de SIG et croisés avec d'autres données ou repositionnés par rapport à des fonds cartographiques de référence.

L'une des premières applications de ces premiers résultats, consistera, pour de futures prospections, à utiliser les résultats de ce modèle dans NetLogo pour définir les zones sur lesquelles porteront préférentiellement les recherches pour un ou deux types de roches siliceuses dans la zone du bassin versant de Manaurie en Dordogne (figure 17) ou encore pour des écoles de terrain à venir dans le cadre des PCR.

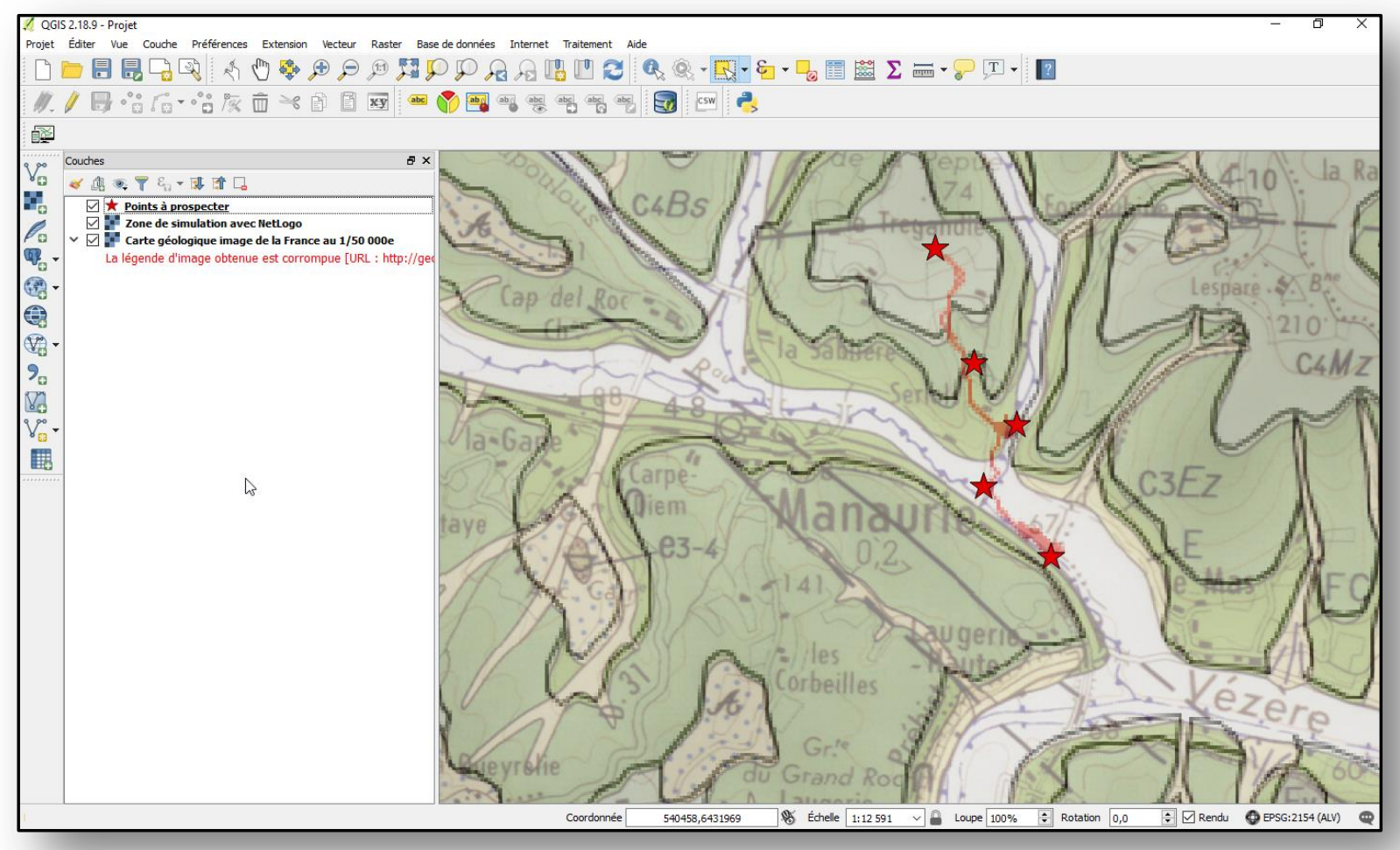

Figure 17. Superposition dans QGis d'un itinéraire calculé dans Netlogo (trait en rouge) et des points (étoiles en rouge) sur lesquels la prospection se concentrera dans le bassin-versant de Manaurie.

\section{Perspectives}

Malgré la simplification de notre modèle, celui-ci semble adapté pour les échelles de résolution spatiale qui nous sont utiles et présentées ici. Pour une prospection à l'échelle d'un sous-bassinversant, l'utilisation de NetLogo et de notre modèle, dérivé du modèle Grand Canyon, permet à

\footnotetext{
${ }^{8}$ En utilisant par exemple la fonction Remplissage qui se trouve dans ArcToolBox>Outils Spatial Analyst $>$ Hydrologie,
} 
l'utilisateur d'identifier des zones de départ possible et/ou des zones de concentration probables dont il a besoin pour préparer ses prospections sur le terrain.

Les premiers résultats de l'utilisation de la modélisation multi-agents, engagée à titre exploratoire cette année, doivent être débattus entre les chercheurs concernés dans les PCR Réseau de lithothèques. Il ne s'agit là que d'une approximation dont des campagnes de prospections sur le terrain devront indiquer le niveau de pertinence et ainsi permettre de valider ou d'infirmer le modèle et les données utilisés pour ces premières simulations.

En particulier, il convient d'évaluer l'intérêt et les possibilités d'application de cette méthode et de cet outil pour la compréhension des parcours naturels des silex dans le cadre de modèles de type gravitaire. Pour valider cette approche, il faut que les prospections prochaines qui seront organisées à partir des résultats de l'utilisation du modèle de NetLogo adapté pour nos besoins, permettent de vérifier que les itinéraires potentiels calculés par le modèle correspondent sur le terrain à une réalité de présence ou d'absence des fragments des roches siliceuses des formations à silex concernées.

Enfin, il pourrait être utile de développer directement dans QGis, probablement en Python, une extension permettant de reproduire les simulations de NetLogo en s'affranchissant ainsi de cet outil. Mais cette possibilité ne sera envisagée qu'après la validation de l'utilisation de la simulation multiagents pour les besoins de prospection mentionnés ici.

\section{Références}

Fernandes P. et Raynal J.-P. (2006) - Pétroarchéologie du silex : un retour aux sources, Comptes rendus Palevol, vol. 5, Issue 6, p. 829-837.

Fernandes, P. (2012) - Itinéraires et transformations du silex : une pétroarchéologie refondée, application au Paléolithique moyen. Thèse de doctorat, Université de Bordeaux 1, 2 volumes, $623 \mathrm{p}$.

Fernandes (dir.), P., Delvigne V., Tuffery C., Beeching A., Bressy-Léandri C., Binder D., Le Bourdonnec F.-X., Queffelec A., Dubernet S., Schmidt P., Platel J.-P., Guibert P., Morala A., Turq A., Querré G., Marchand G., Guiavarc'h M., Léa V., Langlais M., Gibaud A., Jacquier J., Delpuech A., Perrin T., Tomasso A., Moreau L., Vaissié E., Robbe J., Piboule M., Tallet P., Deparnay X., Lafarge A., Cousseran-Néré S., Morin E., Chesnaux L., Guillermin P., V., Raynal J.-P. (2017) - Réseau de lithothèques en Auvergne Rhône-Alpes. Rapport d'opération, Drac LyonClermont-Ferrand, $297 \mathrm{p}$.

Morala A. (dir.), Fernandes P., Turq A., Delvigne V., Tufféry C., Bordes J.-G., Bourguignon L., Caux S., Caverne J.-B., Delage C., Dubernet S., Guibert P., Konik P., Lafarge A., Langlais M., Le Bourdonnec F.-X., Mangado Llach J., Moreau L., Pesesse D., Piboule M., Pinçon G., Platel J.-P., Queffelec A., Sanchez de la Torre M., Schmidt P., Rey Solé M., Talec D., Tallet P., Thiry M., (2016) - Réseau de lithothèques en Nouvelle-Aquitaine. Rapport d'opération, Drac Bordeaux, 139 p.

Tufféry C., Fernandes P., Delvigne V., Morala A., Pinçon G., Konik S. (2017) - Modélisation de données descriptives et spatiales sur les silex pour des projets de recherche collectifs en préhistoire. L'expérience en cours de plusieurs réseaux de lithothèques. Journée d'étude « Modélisation et élaboration conceptuelle de bases de données spatiales en archéologie et en histoire » du réseau ISA. Université de Pau et des pays de l'Adour, laboratoire ITEM. 30/11/2017 et 01/12/2017.

Wilensky, U. (1999) - NetLogo. Center for Connected Learning and Computer-Based Modeling, Northwestern University, Evanston, IL. http://ccl.northwestern.edu/netlogo/.

Wilensky, U. (2006) - NetLogo Grand Canyon model. Center for Connected Learning and Computer-Based Modeling, Northwestern University, Evanston, IL.

http://ccl.northwestern.edu/netlogo/models/GrandCanyon. 